\title{
EVASÃO E PERMANÊNCIA NA EDUCAÇÃO A DISTÂNCIA: FATORES QUE INFLUENCIAM A PERMANÊNCIA DE ESTUDANTES DO CURSO TÉCNICO DE MEIO AMBIENTE DA REDE E-TEC/IFTO
}

\author{
Ana Lúcia Petrocione Jardim ${ }^{1}$ \\ Francisco Gilson Rebouças Pôrto Júnior ${ }^{2}$ \\ Madson Teles de Souza ${ }^{3}$
}

\section{RESUMO}

Este estudo de caso teve por objeto um curso técnico oferecido na modalidade a distância pelo IFTO/Rede e-Tec Brasil, nos polos de educação a distância de Araguatins, Colinas do Tocantins, Palmas e Porto Nacional/To. O objetivo foi conhecer o perfil dos estudantes concluintes e os fatores que contribuíram para a permanência no curso. Foi aplicado um questionário que buscou identificar as características da população pesquisada, e também fatores que tenham contribuído para a permanência dos estudantes no curso. Os resultados obtidos demonstraram que o perfil do grupo pesquisado é em sua maioria do sexo feminino, tem entre vinte e seis e quarenta anos de idade, e a maioria denominou-se parda e com renda familiar de menos de um a dois salários mínimos. Os resultados apontaram que a metodologia das aulas, as avaliações em Educação a Distância (EaD), a atuação do polo, em seu conjunto, foram estatisticamente significativas para a decisão de permanência.

Palavras-chave: Permanência; Educação a Distância; Políticas Públicas de Educação.

\section{DROPOUT AND PERMANENCY IN DISTANCE LEARNING: FACTORS THAT INFLUENCE THE PERMANENCY OF STUDENTS OF THE ENVIRONMENT TECHNICAL COURSE OF THE REDE E- TEC / IFTO}

\begin{abstract}
This case study had as object a technical course offered in distance by IFTO / Rede e-Tec Brasil, in the distance education centers of Araguatins, Colinas do Tocantins, Palmas and Porto Nacional in the State of Tocantins. The objective was to know the profile of the graduating students and the factors that contributed to the permanency in the course. A questionnaire was applied and sought identify characteristics of the researched population and it also factors that have contributed to the permanency in the course. The results showed that the studied group profile is mostly female and it is between twenty-six and forty years old, the most people characterized themselves as brown and with the family income of less than one to two minimum wages. The results also pointed the methodology of the classes and evaluations in distance education, as well as the education centers' action were statistically significant for the decision of permanency in the course.
\end{abstract}

\footnotetext{
${ }^{1}$ Graduada em Letras pelo Centro Universitário Paulistano - SP; Mestre em Gestão de Políticas Públicas (UFT); Especialista em Língua Portuguesa pela Pontifícia Universidade Católica de Minas Gerais (PUC-MG). E-mail: anapetrocione@ifto.edu.br.

${ }^{2}$ Graduado em Comunicação Social/Jornalismo (Ulbra-TO), e em Pedagogia (UnB); Mestre em Educação (UnB); e Doutor em Comunicação e Cultura Contemporânea (UFBA). Orientador do Mestrado Profissional em Gestão de Políticas Públicas (UFT). E-mail: gilsonportouft@gmail.com.

3 Graduado em Administração pela Sociedade Objetivo de Ensino Superior (SOES); Mestre em Administração (USC/PY); Especialista em Auditoria em serviços de saúde pela Universidade Castelo Branco. E-mail: madsonteles@gmail.com
} 
Keywords: Permanency; Distance Learning; Education Public Policies.

\section{EVASIÓN Y PERMANENCIA EN LA EDUCACIÓN A DISTANCIA: FACTORES QUE INFLUYEN EN LA PERMANENCIA DE ESTUDIANTES DEL CURSO TÉCNICO DE MEDIO AMBIENTE DE LA RED E-TEC/IFTO}

\section{RESUMEN}

Este estudio de caso tuvo cómo objeto un curso técnico ofrecido en la modalidad a distancia por IFTO / Rede- e-Tec Brasil, en los polos de Araguatins, Colinas do Tocantins, Palmas y Porto Nacional. El objetivo fue conocer el perfil de los estudiantes de graduación y los factores que han contribuido a mantener el rumbo. Un cuestionario fue utilizado para buscar identificar las características de la población estudiada, y también factores que han contribuido a la permanencia de los estudiantes en el curso. Los resultados mostraron que el perfil del grupo de investigación es en su mayoría mujeres, tienen entre veintiséis y cuarenta años de edad, la mayoría fue nombrada marrón y con un ingreso familiar de menos de uno a dos salarios mínimos. Los resultados mostraron que la metodología de las clases, las evaluaciones de Educación a Distancia (EAD), y la acción de polo, en su conjunto, fueron estadísticamente significativas para la decisión de permanencia.

Palabras-clave: Permanencia; Educación a distancia; Políticas Públicas de Educación.

\section{INTRODUÇÃO}

Permanência e evasão escolar têm sido temas recorrentes em estudos desenvolvidos nas últimas décadas. No entanto, pesquisas direcionadas ao ensino técnico e, ainda, sobre os oferecidos pela Rede e-Tec Brasil /Pronatec ${ }^{4}$ são bastante escassas. Imaginase, então, que a carência de pesquisas nesse sentido se dê porque as políticas implementadas para essa modalidade sejam muito recentes.

Este estudo buscou identificar fatores que, na visão de estudantes concluintes de um curso técnico oferecido na modalidade a distância, foram considerados como cruciais para a persistência no curso. 0 curso pesquisado foi o Técnico em Meio Ambiente ${ }^{5}$, ciclo 20142015, oferecido nos polos de educação a distância de Araguatins, Colinas do Tocantins, Palmas e Porto Nacional pelo Instituto Federal de Educação, Ciência e Tecnologia do Tocantins - IFTO, no âmbito da Rede e-Tec Brasil.

\footnotetext{
${ }^{4}$ O Programa Nacional de Acesso ao Ensino Técnico e Emprego (Pronatec) foi instituído pela Lei no 12.513, de 26 de outubro de 2011 (BRASIL 2011a). A Rede e-Tec Brasil pelo Decreto no 7.589, de 26 de outubro de 2011(BRASIL 2011b). O Pronatec e a Rede e-Tec visam a oportunizar e ampliar a oferta de cursos de educação profissional e tecnológica. Neste estudo utilizamos a forma de expressão Rede e-Tec/Pronatec, compreendendo a Rede e-Tec Brasil como uma das ações (um braço) do Pronatec. ${ }^{5}$ Modalidade: educação profissional, educação a distância. Forma de articulação: subsequente ao Ensino Médio.
} 
O estudo objetivou conhecer o perfil dos estudantes concluintes e verificar, dentre os fatores apontados pelos estudantes, quais incentivaram a permanência, e se consideravam que a metodologia do curso e das avaliações, bem como a atuação do polo tinham influência significativa para sua permanência no curso.

Consideraram-se concluintes, para efeito deste estudo, os estudantes matriculados no terceiro semestre (último) do curso objeto desta pesquisa. Vale ressaltar que o curso Técnico Subsequente em Meio Ambiente, oferecido na modalidade a distância pelo IFTO (ciclo 2014-2015), teve duração de 945h, oferecido em três semestres, e os estudantes, para prosseguirem o curso, deveriam realizar a renovação de matrícula a cada semestre. 0 regulamento do curso impede que estudantes que reprovem por nota ou por falta em qualquer disciplina matriculem-se para o próximo semestre. $O$ estudante que não renovar a matrícula perde o acesso ao ambiente virtual de aprendizagem - Moodle, onde são postadas as aulas e o link para que os estudantes concluintes respondessem ao questionário.

O acesso ao ambiente virtual de aprendizagem demonstrou que, dentre os 200 estudantes que fizeram sua matrícula inicial no curso (50 por polo), somente 121 permaneceram até o terceiro semestre (último do curso), aos quais passaremos a denominar concluintes.

A permanência é aqui considerada como a outra face da problemática da evasão. Como se pode observar em Favero, Coelho e Scremin $(2006,2001,2008)$ e muitos outros, pesquisas sobre permanência de estudantes em cursos têm acompanhado estudos sobre evasão. Compreende-se que as condições que contribuem para permanência do estudante no curso são indissociáveis das que se relacionam com evasão.

\section{EVASÃO E PERMANÊNCIA EM CURSOS OFERECIDOS NA MODALIDADE A DISTÂNCIA}

A evasão escolar é um problema complexo e se relaciona com outros importantes temas da pedagogia, como as formas de avaliação, as metodologias de ensino, o currículo e outros. Os altos índices de evasão motivam pesquisas sobre fatores que contribuam para evasão ou para a permanência. Urge saber o que a escola pode fazer para reverter esse quadro. 
Ana Lúcia Petrocione Jardim Francisco Gilson Rebouças Pôrto Júnior Madson Teles de Souza

O problema do alto índice de evasão nos cursos de Educação a Distância (EaD) afeta, sobretudo, os estudantes, mas não só, pois também as instituições (públicas e privadas) que ministram esses cursos são fortemente impactadas por essa problemática que subverte qualquer planejamento de gestão e investimento, concorrendo para a sua inviabilização.

Bruno (2010, p. 10), retoma Coelho (2010), apresentando supostas causas da evasão no curso a distância, como:

o suficiente domínio técnico do uso do computador (principalmente da internet), falta da tradicional relação face a face entre professores e acadêmicos, dificuldade de expor ideias numa comunicação escrita à distância e a falta de um agrupamento de pessoas numa instituição física.

Para Almeida (2007 apud ABBAD, 2010), a carência de suporte da organização ao estudo pode levar à evasão, da mesma forma que a carência de suporte à aprendizagem.

Na concepção de Abbad (2010, p. 294), existem outros fatores que podem influenciar na evasão do aluno da educação a distância:

O estudo propiciado pela EAD e, em especial, pelo e-learning impõe vários desafios aos pesquisadores desta área. Variáveis de diferentes contextos de estudo do aluno passam a afetar a participação e o rendimento em cursos à distância, o que, consequentemente, deveria resultar em mais pesquisas. Há restrições situacionais do ambiente de trabalho, como: tarefas incompatíveis com o estudo, ruídos, interferências e interrupções, pressões de tempo, conflito de papéis, falta de apoio de chefes a empregados e servidores públicos em treinamentos corporativos. Além desses desafios, o estudante de e- learning, tanto em ambiente organizacional como em acadêmico, está submetido a fatores presentes em outros contextos como o familiar e em outros locais nos quais ele acessa os materiais de estudo. Pouco se sabe sobre a influência de variáveis desse tipo no comportamento e rendimento do estudante de e- learning.

Segundo o Censo EaD.Br (2011), as causas para evasão são a falta de afetividade desenvolvida entre os atores de um curso, falta de acolhimento no polo, o grau de insatisfação do aluno, a falta de conhecimento do curso, dificuldade com a metodologia EaD, complexidade das atividades, dificuldade de assimilação da cultura inerente à EaD, falhas na elaboração do curso, tecnologia inadequada ou falta de habilidade para usar a tecnologia corretamente, ausência de reciprocidade da comunicação, falta de agrupamento de pessoas 
Ana Lúcia Petrocione Jardim Francisco Gilson Rebouças Pôrto Júnior Madson Teles de Souza

em uma instituição física, falta de estímulo, sentimento de incapacidade e solidão, e a falta de dinheiro e tempo.

Segundo Dore (2013, s. p.), “a evasão (abandono escolar) tem uma natureza multiforme: a escolha de sair da escola é apenas o ato final de um processo que se manifesta de muitas formas, visíveis ou não, ao longo da trajetória escolar do indivíduo".

Considerando Brasil - Mec/Setec (2014, p. 19), os motivos que contribuem para a evasão pertencem a mais de uma categoria, podendo estar relacionados a fatores individuais (relacionados à pessoa do estudante), a fatores internos à instituição de ensino (relacionados a professores, a tutores, a coordenadores, à estrutura, à metodologia e ao polo) ou a fatores externos à instituição de ensino (relacionados a questões socioeconômicas e conjunturais).

\section{2 a VALORIZAÇÃo DA EDUCAÇÃo E do TRABALHO EM TEXTOS OFICIAIS E AS POLÍtICAS PÚBLICAS DE EDUCAÇÃO PROFISSIONAL NA MODALIDADE A DISTÂNCIA}

Após a publicação da Constituição da República Federativa do Brasil, de 1988 (CF/88), passa a ser do Estado a responsabilidade de promover a superação das desigualdades. A Constituição de 1988, atendendo a essa nova forma de compreender o mundo e o ser humano, evidencia uma nova concepção de educação, em que haja liberdade de aprender, pluralismo de ideias e formação integral. São princípios para o ensino:

Art. 206. O ensino será ministrado com base nos seguintes princípios:

I - igualdade de condições para o acesso e permanência na escola;

II - liberdade de aprender, ensinar, pesquisar e divulgar o pensamento, a arte e o saber;

III - pluralismo de ideias e de concepções pedagógicas, e coexistência de instituições públicas e privadas de ensino; [...] (BRASIL, 1988).

É a partir da Carta Magna de 1988 que a educação, no Brasil, passa a ser considerada como direito de natureza social, tornando-se tão importante quanto a saúde, a alimentação, o trabalho e outros. 
Ana Lúcia Petrocione Jardim Francisco Gilson Rebouças Pôrto Júnior Madson Teles de Souza

São direitos sociais a educação, a saúde, a alimentação, o trabalho, a moradia, o lazer, a segurança, a previdência social, a proteção à maternidade e à infância, a assistência aos desamparados, na forma desta Constituição (Redação dada pela Emenda Constitucional no 64, de 2010)" (BRASIL, 1988, ART. 6으, grifo nosso).

O direito à educação e ao trabalho podem ser constatados também em:

A educação, direito de todos e dever do Estado e da família, será promovida e incentivada com a colaboração da sociedade, visando ao pleno desenvolvimento da pessoa, seu preparo para o exercício da cidadania e sua qualificação para o trabalho (BRASIL, 1988, art. 205, grifo nosso).

Verifica-se que, na visão dos legisladores da $C F / 88$, a educação, além de ser entendida como fator preponderante para o pleno desenvolvimento da pessoa e para a cidadania, é evidenciada como base para a qualificação do trabalho e como um direito subjetivo: "O acesso ao ensino obrigatório e gratuito é direito público subjetivo" (BRASIL, 1988, Art. 208, § 1ㅇ).

Cabe, ainda, destacar que o trabalho, ao lado da educação e outros direitos, é considerado, na Constituição, como um direito social. Compreende-se, assim, que o Estado, em colaboração com a sociedade, passa a ser responsável pelo alcance dessas metas.

O artigo 227 do texto constitucional enfoca a criança e o adolescente, colocando o Estado, a família e a sociedade como os responsáveis em assegurar os direitos legislados.

Art. 227. É dever da família, da sociedade e do Estado assegurar à criança, ao adolescente e ao jovem, com absoluta prioridade, o direito à vida, à saúde, à alimentação, à educação, ao lazer, à profissionalização, à cultura, à dignidade, ao respeito, à liberdade e à convivência familiar e comunitária, além de colocá-los a salvo de toda forma de negligência, discriminação, exploração, violência, crueldade e opressão. (Redação dada Pela Emenda Constitucional no 65, de 2010) (BRASIL, 1988, grifo nosso).

No texto foram frisadas, além da palavra educação e profissionalização, o verbo assegurar. Para assegurar que a lei se cumpra, não basta estar posta no papel, precisa ser executada. Então são compreendidas duas dimensões para a ação do Estado social: a dimensão negativa, em que ao Estado cabe garantir, através de legislação, a proteção da 
Ana Lúcia Petrocione Jardim

dignidade humana e aos direitos auferidos; e a positiva, em que o Estado deve responsabilizarse pela sua concretização. Impõe-se ao poder público a tarefa de regulamentar e implementar ações que venham concretizar os direitos enunciados (DUARTE, 2007).

Nesse contexto de políticas públicas de educação profissional destacamos, a seguir, as bases legais do Programa Rede e-Tec Brasil, já que o curso analisado por este estudo é um dos cursos oferecidos no âmbito desse programa.

\section{METODOLOGIA DA PESQUISA}

Trata-se de um estudo de caso que se delimita ao Curso Técnico em Meio Ambiente, ciclo 2014-2015, do Programa Rede e-Tec Brasil, oferecido na modalidade a distância IFTO, nos polos de educação a distância de Araguatins, Colinas do Tocantins, Palmas e Porto Nacional - To.

Esta pesquisa de abordagem descritiva tem como objetivo descrever "características de determinada população ou fenômeno ou o estabelecimento de relações entre variáveis" (GIL, 1989, p. 45).

Foi disponibilizado um questionário para acesso dos estudantes concluintes no ambiente virtual de aprendizagem - Moodle, na página inicial do curso Técnico em Meio Ambiente, visando a levantar as características principais da população pesquisada e identificar os fatores que, na visão dos estudantes, incentivaram sua permanência no curso.

Para análise e discussão dos dados obtidos, buscou-se centrar na percepção de três questões levantadas pela pesquisa de campo junto aos cursistas, partindo de estudantes que informaram já ter tido experiência em outros cursos EaD: a) a percepção quanto à metodologia do curso composta por aulas modulares, postagens de aulas, bem como atividades semanais e o próprio formato do ambiente Moodle; b) como esses estudantes percebem a influência da ação do polo na constituição do aprendizado do cursista; e c) como percebem os métodos de avaliação utilizados pelo curso oferecido pelo IFTO.

Dados obtidos por meio das respostas objetivas à Parte II do questionário foram selecionados e tiveram tratamento estatístico a fim de verificar a relação entre já ter feito curso a distância e a percepção das metodologias de aula e de avaliação, bem como da 
importância do polo de apoio presencial na permanência do estudante no curso. Foi feita uma análise comparada de dados recorrendo ao software SPSS ${ }^{6}$ (Statistical Package for Social Science for Windows). Para a comparação dos dados, utilizou-se a correlação de Pearson? .

\section{ANÁLISE E DISCUSSÃO DOS RESULTADOS}

No Moodle, foi possível verificar que os estudantes do curso que se matricularam no primeiro semestre foram 200 , sendo 50 por polo. Observou-se que os que renovaram sua matrícula para o segundo e para o terceiro semestre foram 121 estudantes. Dessa forma, no curso, ciclo 2014-2015, houve 79 evadidos até a data da pesquisa. A taxa de permanência no terceiro semestre foi de $60,5 \%$.

Do total de 121 estudantes concluintes, 97 responderam ao questionário, o que pode ser considerado um excelente nível de participação (80,16\%). Essa alta taxa de participação se deu provavelmente pelo contato que foi feito com as coordenações e tutoria dos polos, solicitando que incentivassem os estudantes a participar da pesquisa, aproveitando principalmente as ocasiões da vinda ao polo para atividades/avaliações presencias.

\subsection{Perfil dos respondentes}

A seguir são apresentados gráficos com resultados selecionados da Parte I do questionário - Perfil dos Estudantes Concluintes:

\footnotetext{
${ }^{6}$ Licenciado pela IBM/SPSS para o orientador desta pesquisa. Esse programa da International Business Machines (IBM) possui ferramentas para análise estatística que permitem realizar procedimentos para esclarecer relacionamentos entre variáveis e identificar tendências.

${ }^{7} \mathrm{O}$ coeficiente de correlação de Pearson é uma medida do grau de relação linear entre duas variáveis quantitativas. Este coeficiente varia entre os valores -1 e 1 . O valor 0 (zero) significa que não há relação linear, o valor 1 indica uma relação linear perfeita e o valor -1 também indica uma relação linear perfeita mas inversa, ou seja quando uma das variáveis aumenta, a outra diminui. Quanto mais próximo estiver de 1 ou -1, mais forte é a associação linear entre as duas variáveis.
} 
Ana Lúcia Petrocione Jardim Francisco Gilson Rebouças Pôrto Júnior Madson Teles de Souza

\section{Gráfico 1 - Sexo dos concluintes}

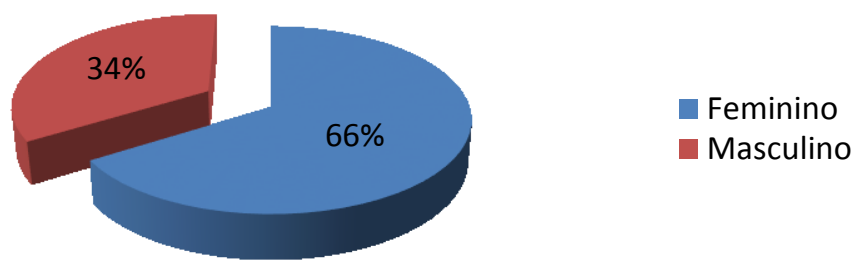

Fonte: Pesquisa, 2015.

Dos 97 respondentes, verificou-se predominância do sexo feminino em 66\% (64 indivíduos), em relação ao sexo masculino, 34\% (33 indivíduos).

\section{Gráfico 2 - Idade dos concluintes}

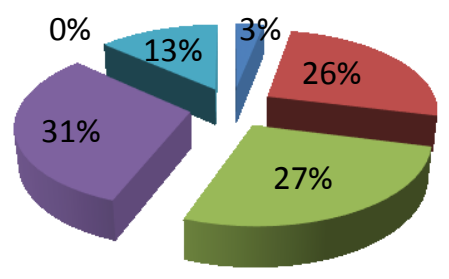

$$
\begin{aligned}
& \text { Faixa Etária } \\
& -14 \text { a } 19 \text { anos } \\
& 20 \text { a } 25 \text { anos } \\
& -26 \text { a } 30 \text { anos } \\
& -31 \text { a } 40 \text { anos } \\
& 41 \text { ou mais }
\end{aligned}
$$

Fonte: Pesquisa, 2015.

Dos 97 respondentes, verificou-se predominância de estudantes já adultos, ou seja, que possuem entre 26 a 40 anos, compondo um total de $58 \%$.

\section{Gráfico 3 - Cor da pele}

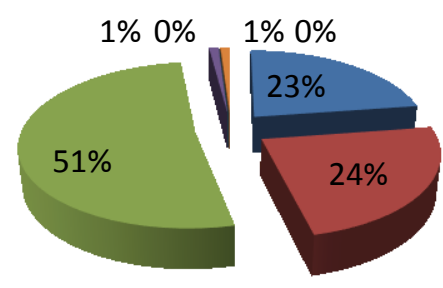
- Cor da Pele
- Preta
Branca
- Parda
Amarela/descendente de orientais

Fonte: Pesquisa, 2015. 
A predominância de concluintes é de cor parda. Denominaram-se: 23 brancos (24\%); 50 pardos (51\%); 23 pretos (23\%); 1 amarelo (oriental ou descendente de oriental). Não há indígenas dentre os concluintes.

\section{Gráfico 4 - Renda Média}

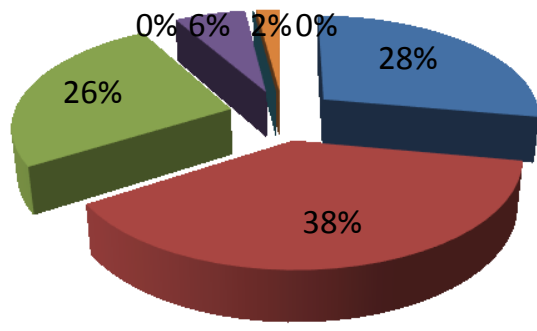

Renda

Até 1

de 1 a 2

de 3 a 5

de 6 a 10

Acima de 10

não sei informar

Fonte: Pesquisa, 2015.

Dos respondentes, verifica-se que a maioria possui baixa renda, pois $56 \%$ do total de concluintes informaram que a renda familiar é de $<1$ até 2 salários mínimos.

\subsection{Relação entre experiência em EaD e permanência no curso}

Uma das questões desta pesquisa buscou identificar se os estudantes que já haviam feito outros cursos na modalidade a distância seriam ou não os que melhor avaliariam, ou mesmo se seriam mais influenciáveis pelo processo de formação a distância. A ideia inicial era que a metodologia do curso, composta por aulas modulares, postagens de aulas, bem como atividades semanais e o próprio formato do ambiente Moodle, favoreceriam a aprendizagem e isso seria perceptível pelo alunado. Na Tabela 1, a seguir, temos uma visão:

\section{Tabela 1 - Experiência em cursos EaD e a influência da metodologia para favorecimento do aprendizado}

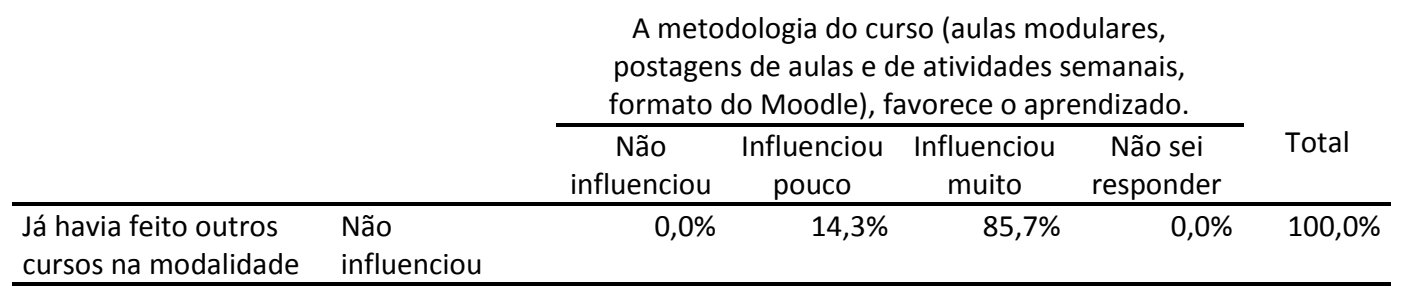


Ana Lúcia Petrocione Jardim Francisco Gilson Rebouças Pôrto Júnior Madson Teles de Souza

\begin{tabular}{llccccc}
\hline a distância e isso me & $\begin{array}{l}\text { Influenciou } \\
\text { ajudou com as } \\
\text { tecnologias e/ou }\end{array}$ & $8,3 \%$ & $41,7 \%$ & $41,7 \%$ & $8,3 \%$ & $100,0 \%$ \\
\cline { 2 - 7 } $\begin{array}{l}\text { metodologias } \\
\text { utilizadas. }\end{array}$ & $\begin{array}{l}\text { Influenciou } \\
\text { muito }\end{array}$ & $4,8 \%$ & $23,8 \%$ & $71,4 \%$ & $0,0 \%$ & $100,0 \%$ \\
\cline { 2 - 7 } & $\begin{array}{l}\text { Não sei } \\
\text { responder }\end{array}$ & $13,3 \%$ & $13,3 \%$ & $66,7 \%$ & $6,7 \%$ & $100,0 \%$ \\
\hline Total & & $5,2 \%$ & $21,6 \%$ & $71,1 \%$ & $2,1 \%$ & $100,0 \%$ \\
\hline
\end{tabular}

Fonte: Pesquisa de campo, 2015.

Destaca-se que, dentro dos que já haviam feito cursos na modalidade a distância e que afirmaram que as tecnologias e/ou metodologias utilizadas não tiveram influência, $85,7 \%$ desses reconhecem que a metodologia do ambiente teve influência em seu aprendizado. As diferenças quanto ao tipo de influência em geral não são grandes, mas em seu conjunto são estatisticamente significativas ao nível de pelo menos $1 \%(p<=0,01)^{8}$. É interessante, pois os que afirmaram que tiveram pouca $(41,7 \%)$ ou muita influência $(71,4 \%)$ por terem experiência anterior em ambientes EaD, externam um impacto bem menor em sua percepção de aprendizado quando percebem a metodologia do curso e os aspectos complementares criados em torno do ambiente.

Outra questão comumente apontada nos estudos sobre evasão e permanência em Educação a Distância é a ação do polo na constituição do aprendizado do cursista.

Tabela 2 - Experiência em cursos EaD e a influência da ação do polo

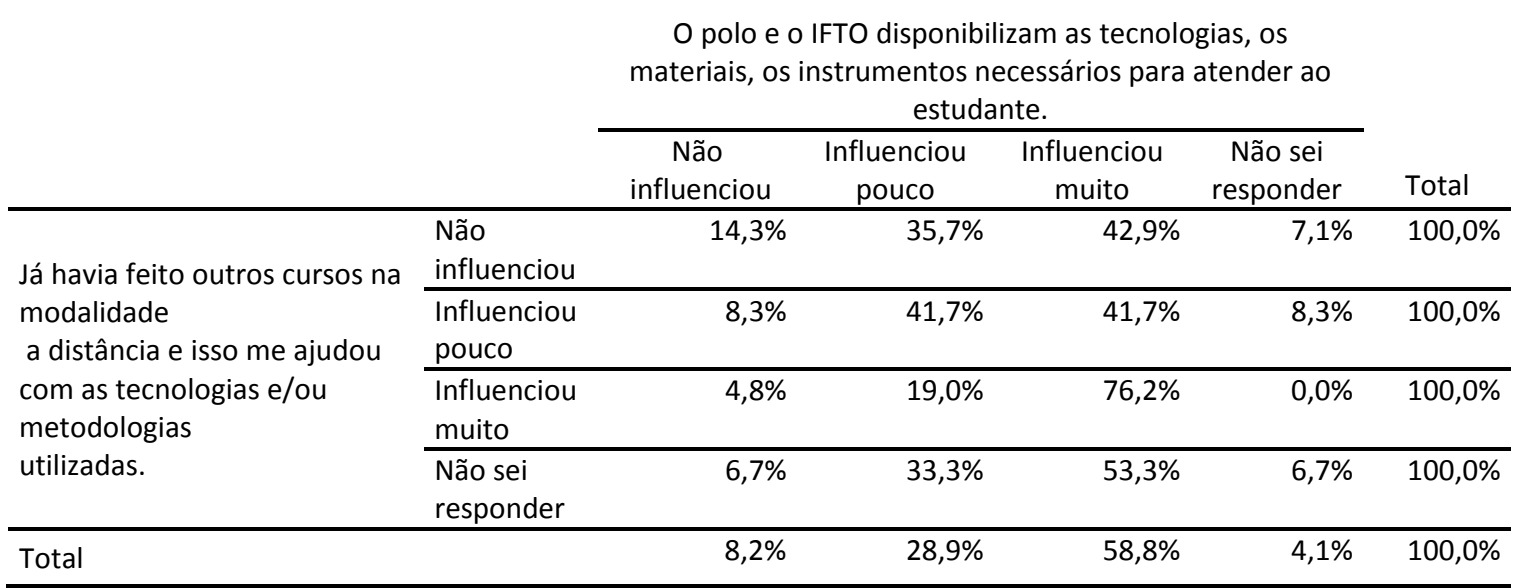

Fonte: Pesquisa de campo, 2015.

$8 \quad$ Na correlação de Pearson o índice foi de $(-, 111)$; a soma dos quadrados e produtos cruzados ficou em $(-6,845)$ e a covariância de $(-, 071)$. O intervalo de confiança de $95 \%$ teve variação superior de $(, 074)$, levando em consideração a amostragem de 97 pesquisados. 
Ana Lúcia Petrocione Jardim Francisco Gilson Rebouças Pôrto Júnior Madson Teles de Souza

Percebe-se o reconhecimento de que a atuação permanente do polo em assegurar os meios para o aprendizado é essencial para a permanência do cursista. Isso é perceptível aos $76,2 \%$ dos que já tinham experiência em formação EaD e que afirmaram que a ação do polo disponibilizando tecnologias, materiais e outros instrumentos necessários teve muita influência. As diferenças quanto ao tipo de influência em geral, nesse quesito, também não são grandes, mas em seu conjunto são estatisticamente significativas ao nível de pelo menos $1 \%(p<=0,01)^{9}$. Destaca-se que, apesar da influência (pouca ou muita) chegar a quase $88 \%$ da amostragem, os que parecem estar excluídos do processo de compreensão da $\mathrm{EaD}$, isto é, os que conseguiram apreender competências e habilidades via EaD anteriormente, mas que afirmaram que não influenciou (14,3\%) ou que influenciou pouco (8,3\%), quando observam a ação do polo, do IFTO e toda a estrutura disponibilizada, geram preocupação.

O bom funcionamento do polo, compreendido aqui como estrutura física e também como local de acolhimento do estudante pela coordenação do polo e pelos tutores presenciais, é especialmente importante para o desenvolvimento das atividades presenciais, para que os estudantes se encontrem com seu grupo, para que tenham acolhimento em suas necessidades pedagógicas e inclusive afetivas. Ferreira e Shiller (2011), Souza (2004) e vários outros autores destacam a importância da afetividade e acolhimento por parte de professores e tutores na modalidade a distância.

A última questão levantada nessa pesquisa refere-se a como os alunos percebem os métodos de avaliação utilizados pelo curso oferecido pelo IFTO. Esta também é uma questão importante na EaD. Ocorre que em cursos presenciais o feedback dos estudantes em relação ao formato de uma avaliação geralmente é imediato, já que estudante e professor estão presentes nesse momento. Em cursos a distância esse feedback pode ser dificultado, visto que estudante e professor encontram-se em espaços diversos no momento avaliativo. Neste estudo, a Tabela 3, a seguir, mostra o impacto nessa questão.

\section{Tabela 3 - Experiência em cursos EaD e a percepção sobre a adequação dos métodos avaliativos}

Os métodos de avaliação são adequados

$9 \quad$ Na correlação de Pearson o índice foi de $(, 140)$, sendo que a soma dos quadrados e produtos cruzados ficou em 10,144$)$ e a covariância de $(, 106)$. O intervalo de confiança de $95 \%$ teve variação superior de $(, 435)$, levando-se em consideração a amostragem de 97 pesquisados. 
Ana Lúcia Petrocione Jardim Francisco Gilson Rebouças Pôrto Júnior Madson Teles de Souza

\begin{tabular}{|c|c|c|c|c|c|c|}
\hline & & $\begin{array}{c}\text { Não } \\
\text { influenciou }\end{array}$ & $\begin{array}{c}\text { Influenciou } \\
\text { pouco }\end{array}$ & $\begin{array}{c}\text { Influenciou } \\
\text { muito }\end{array}$ & $\begin{array}{c}\text { Não sei } \\
\text { responder }\end{array}$ & Total \\
\hline \multirow{4}{*}{$\begin{array}{l}\text { Já havia feito outros cursos } \\
\text { na modalidade } \\
\text { a distância e isso me } \\
\text { ajudou com as tecnologias } \\
\text { e/ou metodologias } \\
\text { utilizadas. }\end{array}$} & $\begin{array}{l}\text { Não } \\
\text { Influenciou }\end{array}$ & $0,0 \%$ & $25,0 \%$ & $75,0 \%$ & $0,0 \%$ & $100,0 \%$ \\
\hline & $\begin{array}{l}\text { Influenciou } \\
\text { pouco }\end{array}$ & $8,3 \%$ & $50,0 \%$ & $33,3 \%$ & $8,3 \%$ & $100,0 \%$ \\
\hline & $\begin{array}{l}\text { Influenciou } \\
\text { Muito }\end{array}$ & $4,8 \%$ & $16,7 \%$ & $78,6 \%$ & $0,0 \%$ & $100,0 \%$ \\
\hline & $\begin{array}{l}\text { Não sei } \\
\text { responder }\end{array}$ & $6,7 \%$ & $20,0 \%$ & $73,3 \%$ & $0,0 \%$ & $100,0 \%$ \\
\hline Total & & $4,1 \%$ & $23,7 \%$ & $71,1 \%$ & $1,0 \%$ & $100,0 \%$ \\
\hline
\end{tabular}

Fonte: Pesquisa de campo, 2015.

A avaliação da aprendizagem e sua adequação ao modelo EaD é uma das atividades mais complexas do processo de formação. Esta é uma preocupação dos envolvidos no Curso Técnico Subsequente em Meio Ambiente, ciclo 2014, do Programa Rede e-Tec Brasil, oferecido na modalidade a distância pelo IFTO, no polo Palmas - TO. Percebe-se que, na visão dos que já tiveram experiência em $\mathrm{EaD}, 78,6 \%$ afirmaram que os métodos de avaliação eram adequados. As diferenças quanto ao tipo de influência em geral, nesse quesito, também não são grandes, mas em seu conjunto são estatisticamente significativas ao nível de pelo menos $1 \%(p<=0,01)^{10}$. Mesmo os que já tiveram experiência e que afirmam não sentir influência dessa formação, reconhecem em $75 \%$ dos respondentes que os métodos são adequados, em sua percepção. Destaca-se que a influência (pouca ou muita) chega a quase $95 \%$ da amostragem. Mesmo entre todos os que afirmaram não ser influenciados, mais de $13 \%$ reconhecem (pouco ou muito) a adequação dos métodos de avaliação.

Vale ressaltar a importância de que professores e gestores de políticas públicas educacionais busquem informações sobre como está a percepção dos estudantes sobre a metodologia utilizada nas aulas e nas avaliações de aprendizagem. Saber se o estudante considera ou não apropriados os métodos utilizados favorecerá discussão sobre a necessidade de ajustes na formatação e na metodologia de ensino e de avaliações. O polo também deve ser objeto de estudos, pois é uma extensão do campus ofertante, sendo necessário conhecer como o estudante percebe esse espaço.

\footnotetext{
10 Na correlação de Pearson o índice foi de (,140), a soma dos quadrados e produtos cruzados ficou em 10,144), e a covariância de (,106). O intervalo de confiança de $95 \%$ teve variação superior de (,357), considerando a amostragem de 97 pesquisados.
} 


\section{CONSIDERAÇÕES FINAIS}

Novas demandas surgiram no mundo globalizado, sinalizando que vivenciamos uma fase de transição. Verifica-se que o planejamento das políticas públicas educacionais de Ensino Médio profissionalizante vem considerando a educação a distância como um meio bastante viável de alcançar uma educação abrangente, com inclusão social e consequente desenvolvimento dos municípios.

As políticas públicas, além buscarem o desenvolvimento econômico do país e de cada município, devem ser implementadas de maneira a buscar sempre a formação plena de cidadãos, de seres humanos que sejam capazes de se integrar ao novo contexto. Assim, urge uma formação técnica profissionalizante para atender ao maior número possível de indivíduos, bem como a uma economia mundialmente integrada, mas entende-se que essa formação técnica não pode ser mecânica e nem deve tornar-se um fim em si.

Verificou-se que a taxa de permanência no Curso Técnico Subsequente em Meio Ambiente (ciclo 2014-2015), oferecido na modalidade a distância pelo IFTO no âmbito da Rede E-tec Brasil foi acentuada, indicando bom desempenho do curso. Alguns fatores, no entanto, percebidos por estudantes que já fizeram outros cursos a distância sinalizaram para que a questão da metodologia do curso e das avaliações, bem como o funcionamento dos polos sejam objeto de constante avaliação por parte dos gestores.

Percebeu-se, também, pelo perfil dos estudantes concluintes, a importância dessa política pública para a região. Muito provavelmente, esses indivíduos que apontaram ser a maioria dos concluintes, com idade entre 26 a 40 anos de idade e renda na faixa de um a dois salários mínimos não tiveram e não teriam oportunidade de formação profissional fora de seu município.

Mesmo com a expansão do ensino, inclusive do ensino na modalidade a distância, sabe-se que ainda há, no Brasil, significativa parcela da população carente de educação e formação para o trabalho. Assim, é importante que gestores de políticas públicas de educação empenhem seus esforços em conhecer os fatores que conduzem à evasão e que favorecem a permanência. Para que as políticas públicas alcancem seus objetivos, deverão ser acompanhadas e avaliadas. 
Ana Lúcia Petrocione Jardim

A evasão é, sem dúvida, um prejuízo para a instituição, seja ela pública ou privada. Sem dúvida, faz-se necessário que se invista em políticas de permanência com o oferecimento de metodologias de aula e de avaliação adequadas, bem como estruturas nos polos de educação a distância que atendam às necessidades dos estudantes.

\section{REFERÊNCIAS}

ABBAD, Gardênia da Silva; ZERBINI, Thais; SOUZA, Daniela Borges Lima de. Panorama das pesquisas em educação á distância no Brasil. In: Estudos de Psicologia, 15(3), setembrodezembro/2010. Disponível em: <http://www.scielo.br/epsic >. Acesso em: 15 out. 2011.

BRASIL. Constituição da República Federativa do Brasil: promulgada em 5 de outubro de 1988. Disponível em: <http://www.planalto.gov.br/ccivil 03/constituicao/constituicao.htm>. Acesso em: 30 jul. 2014.

. Decreto 2.494, de 10 de fevereiro de 1998. [Revogado]. Regulamenta o Art. 80 da LDB (Lei n.o 9.394/96). Disponível em:

<http://portal.mec.gov.br/seed/arquivos/pdf/tvescola/leis/D2494.pdf>. Acesso em: 2 ago. 2014.

. Decreto 5.622, de 19 de dezembro de 2005. Regulamenta o art. 80 da Lei no 9.394, de 20 de dezembro de 1996, que estabelece as diretrizes e bases da educação nacional. Disponível em: < http://www.planalto.gov.br/ccivil 03/ ato20042006/2005/Decreto/D5622.htm>. Acesso em: 2 ago. 2014.

. Decreto no 7.589, de 26 de outubro de 2011. (2011b) Institui a Rede e-Tec Brasil. Disponível em: <http://www.planalto.gov.br/ccivil 03/ Ato20112014/2011/Decreto/D7589.htm>. Acesso em: 4 ago. 2014.

. Lei n. 8.069, de 13 de julho de 1990. Dispõe sobre o Estatuto da Criança e do Adolescente e dá outras providências. Disponível em: <http://www.planalto.gov.br/ccivil 03/leis/l8069.htm>. Acesso em: 19 mar. 2015.

. Lei n. 9.394, de 20 de dezembro de 1996. Estabelece as diretrizes e bases da educação nacional. Disponível em: <http://www.planalto.gov.br/ccivil 03/leis/19394.htm>. Acesso em: 10 ago. 2014.

. Lei no 12.513, de 26 de outubro de 2011. Institui o Programa Nacional de Acesso ao Ensino Técnico e Emprego (Pronatec) e dá outras providências. Disponível em: <http://pronatec.mec.gov.br/institucional-90037/objetivos-e-iniciativas $>$. Acesso em: 5 jan. 2014. 
. Plano de Desenvolvimento da Educação - PDE. Disponível em:

<http://portal.mec.gov.br/arquivos/livro/livro.pdf>. Acesso em: 6 dez. 2014.

BRASIL. MEC. Portal da Rede e-Tec. Disponível em:

$<$ http://redeetec.mec.gov.br/index.php/2-e-tec/conteudo-centro/1-objetivos-da-educacaoprofissional-tecnica>. Acesso em: 8 ago. 2014.

BRASIL/MEC/PRONTATEC. Programa Nacional de Acesso ao Ensino Técnico e Emprego. Disponível em: <http://pronatec.mec.gov.br/institucional-90037/objetivos-e-iniciativas $>$. Acesso em: 10. mai. 2015.

BRUNO, G. Jorge (et all.). Evasão na educação á distância: um estudo sobre a evasão em uma instituição de ensino superior. Disponível em:

$<$ http://www.abed.org.br/congresso2010/cd/2520102204050.pdf >. Acesso em: 20 mai. 2015.

DORE, Rosemary. Evasão e Repetência na Rede Federal de Educação Profissional. XXXVII REDITEC - Maceió, AL. 2013. Disponível em: <http://www.reditec.ifal.edu.br/arquivos1/apresentacoes/dia-04-09/>. Acesso em: 19 mar. 2015.

DUARTE, Clarice Seixas. A Educação como um direito Fundamental de Natureza Social. Revista Educação \&. Sociedade. Cedes: Unicamp, Campinas, vol. 28, no 100 Especial, out. 2007. Disponível em: <http://www.scielo.br/pdf/es/v28n100/a0428100>. Acesso em: 19 fev. 2015.

FERREIRA, Sandra Mara Bessa; SHILER, Anelise Pereira. A afetividade mediada por meio da interação na modalidade a distância como fator preponderante para a diminuição da evasão. In: 17ํ CIAED - Congresso Internacional ABED de Educação a Distância, 2011, Manaus. 17ํㅜ CIAED -

GIL, Antônio Carlos. Métodos e Técnicas de Pesquisa Social. Editora Atlas S.A, 1989, São Paulo.

SOUZA, Matias Gonzalez de. Arte da Sedução Pedagógica na Tutoria em Educação a Distância. Congresso Abed, 2004. Disponível em: <http://www.abed.org.br/congresso2004/por/htm/001-TC-A1.htm>. Acesso em 7 mai. 2015.

RECEBIDO EM 06 DE OUTUBRO DE 2016.

APROVADO EM 31 DE OUTUBRO DE 2016. 